\title{
Are stentless valves hemodynamically superior to stented valves? Long-term follow-up of a randomized trial comparing Carpentier- Edwards pericardial valve with the Toronto Stentless Porcine Valve
}

Gideon Cohen, MD, PhD, Brandon Zagorski, MSc, George T. Christakis, MD, Campbell D. Joyner, MD, Jessica Vincent, Jeri Sever, Sumaya Harbi, MD, Randi Feder-Elituv, Fuad Moussa, MD, Bernard S. Goldman, MD, and Stephen E. Fremes, MD

Objective: The benefit of stentless valves remains in question. In 1999, a randomized trial comparing stentless and stented valves was unable to demonstrate any hemodynamic or clinical benefits at 1 year after implantation. This study reviews long-term outcomes of patients randomized in the aforementioned trial.

Methods: Between 1996 and 1999, 99 patients undergoing aortic valve replacement were randomized to receive either a stented Carpentier-Edwards pericardial valve (CE) (Edwards Lifesciences, Irvine, Calif) or a Toronto Stentless Porcine Valve (SPV) (St Jude Medical, Minneapolis, Minn). Among these, 38 patients were available for late echocardiographic follow-up $(\mathrm{CE}, \mathrm{n}=17$; SPV, $\mathrm{n}=21)$. Echocardiographic analysis was undertaken both at rest and with dobutamine stress, and functional status (Duke Activity Status Index) was compared at a mean of 9.3 years postoperatively (range, 7.5-11.1 years). Clinical follow-up was $82 \%$ complete at a mean of 10.3 years postoperatively (range, 7.5-12.2 years).

Results: Preoperative characteristics were similar between groups. Effective orifice areas increased in both groups over time. Although there were no differences in effective orifice areas at 1 year, at 9 years, effective orifice areas were significantly greater in the SPV group $\left(\mathrm{CE}, 1.49 \pm 0.59 \mathrm{~cm}^{2} ; \mathrm{SPV}, 2.00 \pm 0.53 \mathrm{~cm}^{2} ; P=\right.$ .011). Similarly, mean and peak gradients decreased in both groups over time; however, at 9 years, gradients were lower in the SPV group (mean: CE, $10.8 \pm 3.8 \mathrm{~mm} \mathrm{Hg}$; SPV, $7.8 \pm 4.8 \mathrm{~mm} \mathrm{Hg} ; P=.011$; peak: CE, $20.4 \pm 6.5 \mathrm{~mm} \mathrm{Hg}$; SPV, $14.6 \pm 7.1 \mathrm{~mm} \mathrm{Hg} ; P=.022)$. Such differences were magnified with dobutamine stress (mean: CE, $22.7 \pm 6.1 \mathrm{~mm} \mathrm{Hg}$; SPV, $15.3 \pm 8.4 \mathrm{~mm} \mathrm{Hg} ; P=.008$; peak: CE, $48.1 \pm 11.8 \mathrm{~mm} \mathrm{Hg}$; $\mathrm{SPV}, 30.8 \pm 17.7 \mathrm{~mm} \mathrm{Hg} ; P=.001)$. Ventricular mass regression occurred in both groups; however, no differences were demonstrated between groups either on echocardiographic, magnetic resonance imaging, or biochemical (plasma B-type [brain] natriuretic peptide) assessment $(P=.74)$. Similarly, Duke Activity Status Index scores of functional status improved in both groups over time; however, no differences were noted between groups (CE, $27.5 \pm 19.1 ; \mathrm{SPV}, 19.9 \pm 12.0 ; P=.69)$. Freedom from reoperation at 12 years was $92 \% \pm 5 \%$ in patients with CEs and $75 \% \pm 5 \%$ in patients with SPVs $(P=.65)$. Freedom from valverelated morbidity at 12 years was $82 \% \pm 7 \%$ in patients with CEs and $55 \% \pm 7 \%$ in patients with SPVs $(P=.05)$. Finally, 12-year actuarial survival was $35 \% \pm 7 \%$ in patients with CEs and $52 \% \pm 7 \%$ in patients with SPVs $(P=.37)$.

Conclusion: Although offering improved hemodynamic outcomes, the SPV did not afford superior mass regression or improved clinical outcomes up to 12 years after implantation. (J Thorac Cardiovasc Surg 2010;139:848-59)

Despite numerous advances in surgical technique, aortic valve replacement (AVR) for isolated aortic valve disease does not achieve a normalization of long-term outcomes. ${ }^{1-8}$ Stentless valves were designed to provide optimal hemodynamic and clinical outcomes while improving long-term

From the Division of Cardiovascular Surgery at Sunnybrook Health Sciences Centre and the University of Toronto, Toronto, Ontario, Canada.

Disclosures: None.

Supported by the Heart and Stroke Foundation of Canada.

Read at the Eighty-eighth Annual Meeting of The American Association for Thoracic Surgery, San Diego, Calif, May 10-14, 2008.

Received for publication May 7, 2008; revisions received March 8, 2009; accepted for publication April 27, 2009; available ahead of print Jan 18, 2010. prosthetic durability. Presumably, elimination of the valvular sewing ring and stent would facilitate implantation of a prosthesis that was 1 to 3 sizes larger than would otherwise be possible with a conventional stented bioprosthesis. ${ }^{9}$ This would result in larger effective orifice areas (EOAs) and reduced

\footnotetext{
Address for reprints: Gideon Cohen, MD, PhD, Sunnybrook Health Sciences Centre, H-429, 2075 Bayview Ave, Toronto, Ontario, Canada M4 N 3M5 (E-mail: gideon. cohen@sunnybrook.ca). 0022-5223/\$36.00

Copyright (C) 2010 by The American Association for Thoracic Surgery doi:10.1016/j.jtcvs.2009.04.067
} 


$$
\begin{aligned}
& \text { Abbreviations and Acronyms } \\
& \text { AI }=\text { aortic insufficiency } \\
& \text { AVR }=\text { aortic valve replacement } \\
& \text { BNP }=\text { B-type (brain) natriuretic peptide } \\
& \text { CE } \quad \text { Carpentier-Edwards (stented) Perimount } \\
& \\
& \text { valve } \\
& \text { DASI }=\text { continuous wave } \\
& \text { EOA }=\text { effective orifice area } \\
& \text { LV }=\text { left ventricular } \\
& \text { LVMI }=\text { left ventricular mass index } \\
& \text { LVOT }=\text { left ventricular outflow tract } \\
& \text { MRI }=\text { magnetic resonance imaging } \\
& \text { NYHA }=\text { New York Heart Association } \\
& \text { PW }=\text { pulsed wave } \\
& \text { SPV }=\text { Toronto Stentless Porcine Valve } \\
& \text { 2D }=\text { 2-dimensional }
\end{aligned}
$$

transvalvular gradients. Ventricular mass would regress more completely, resulting in improved survival and functional outcomes. Finally, optimized hemodynamic profiles and enhanced leaflet motion would improve overall valvular durability and minimize the need for reoperation..$^{10-13}$

Although such improvements were expected with the advancements in prosthetic design, much controversy exists regarding the true hemodynamic and clinical effect of stentless valves. To date, numerous comparative studies have been undertaken. ${ }^{14-17}$ However, results are disparate, and no clear clinical advantage of one valve type over another has been demonstrated.

In 1996, our group attempted to address this ongoing controversy by conducting a randomized trial of stented versus stentless valves. ${ }^{18}$ Ninety-nine patients undergoing primary elective bioprosthetic AVR were randomized to receive either the Carpentier-Edwards (stented) Perimount valve (CE; Edwards Lifesciences, Irvine, Calif) or the Toronto Stentless Porcine Valve (SPV; St Jude Medical, Minneapolis, Minn).

At 1 year postoperatively, although a reduction in peak and mean transvalvular gradients and an increase in EOAs was demonstrated in both groups, no differences were noted between groups. Not unexpectedly, resolution of the underlying stenosis resulted in regression of left ventricular (LV) mass over time in both groups. However, once again, no differences were noted between groups. Finally, Duke Activity Status Index (DASI) scores improved significantly over time in both groups. Although scores were slightly higher in the stented group at 3 months postoperatively, no differences were noted between groups at 1 year postoperatively.

In light of the above findings, we concluded that the advantages of stentless valves, if any, were unlikely to be revealed in the short-term and could only be elucidated through long-term follow-up of echocardiographic parameters, patient outcomes, and valvular durability. To this end, we undertook a long-term follow-up of patients randomized in the aforementioned trial.

\section{MATERIALS AND METHODS}

A retrospective analysis was undertaken involving patients who participated in a prospective randomized trial of stentless (SPV) versus stented (CE) valves between September 1996 and December 1999 to determine whether implantation of stentless valves resulted in improved ventricular mass regression, improved hemodynamic indices, and improved clinical outcomes up to 12 years after AVR. Table 1 summarizes the clinical profiles of all patients by group. Methods of implantation, inclusion/exclusion criteria, and randomization protocols have been previously described. ${ }^{18}$

\section{Patient Follow-up}

Preoperative, postoperative, and 3- and 12-month patient characteristics were extracted from databases constructed during the initial (1 year) and follow-up phases of this randomized trial. Appropriate institutional research ethics board approval was obtained for contacting patients. At first contact, patients were informed of the study in question and provided initial verba consent by telephone. If the patient agreed to participate, the entire process, including written consent, was repeated during a follow-up office visit.

\section{Clinical Outcomes}

Clinical assessment of consented patients was performed in person by means of physical assessment and facilitated by a standardized postoperative follow-up questionnaire designed to assess current cardiac medications, New York Heart Association (NYHA) functional status, and cardiac morbidity, including hospital/outpatient visits and repeat valve surgery. On receiving the patient's consent, routine blood work was performed to preclude the presence of confounding variables that might have adversely affected the patient's well-being, cardiac function, or both (eg, anemia or renal insufficiency). Those patients not available for telephone or echocardiographic follow-up were followed through linkage of health card numbers to various governmental registries. Because of Ontario's "single-provider" health care system, such linkage offered accurate information regarding mortality, diagnoses, readmissions, and reinterventions.

Valve-related complications were reported according to standardized methods established by the Society of Thoracic Surgeons and the American Association of Thoracic Surgeons. ${ }^{19,20}$ Events were categorized as structural or nonstructural valve deterioration, valve thrombosis, embolic events, bleeding events, and/or prosthetic valve endocarditis.

\section{Measurements and Calculations}

Two-dimensional echocardiographic protocol and measurements. Transthoracic 2-dimensional (2D) echocardiographic measurements were performed on all available patients at follow-up, with comparison with measurements obtained at 3 and 12 months postoperatively. Echocardiographic parameters and calculations are provided in Appendix 1. Examination included 2D, 2D-derived M-mode, and color Doppler analyses. Left parasternal, apical right parasternal, subcostal, and suprasternal standard views were used in a successive pattern of interrogation. All measurements were averaged over 3 cardiac cycles in sinus rhythm, and 6 cardiac cycles were used in cases of atrial fibrillation. Only 2 sonographers were used for this study, both having been previously assessed for less than 5\% interobserver variability. All readings were performed by 2 experienced echocardiographers, both of whom were 
TABLE 1. Preoperative patient characteristics

\begin{tabular}{lccc}
\hline & CE $(\mathbf{n}=\mathbf{5 3})$ & SPV $(\mathbf{n}=\mathbf{4 6})$ & $\boldsymbol{P}$ value \\
\hline Age $(\mathrm{y})$ & $69.0 \pm 7.6$ & $71.8 \pm 7.1$ & .07 \\
Age $>70$ y & $24(45.3 \%)$ & $29(63.0 \%)$ & .1060 \\
Female sex & $20(37.7 \%)$ & $15(32.6 \%)$ & .6754 \\
BSA $\left(\mathrm{m}^{2}\right)$ & $1.86 \pm 0.23$ & $1.88 \pm 0.24$ & .7040 \\
Urgent operation & $5(9.4 \%)$ & $6(13.0 \%)$ & .7503 \\
NYHA class III-IV & $37(69.9 \%)$ & $38(82.6 \%)$ & .1634 \\
CHF & $8(15.1 \%)$ & $6(13.0 \%)$ & 1.00 \\
Diabetes & $7(13.2 \%)$ & $6(13.0 \%)$ & .7674 \\
Hypertension & $25(47.2 \%)$ & $23(50.0 \%)$ & .8415 \\
CRF & $2(3.8 \%)$ & $4(8.7 \%)$ & .4122 \\
CCS class III-IV & $10(18.9 \%)$ & $8(17.4 \%)$ & 1.00 \\
COPD & $3(5.7 \%)$ & $3(6.5 \%)$ & 1.00 \\
PVD & $6(11.3 \%)$ & $6(13.0 \%)$ & 1.00 \\
Ejection fraction $<40 \%$ & $4(7.6 \%)$ & $4(8.7 \%)$ & 1.00 \\
CAD & $21(39.6 \%)$ & $18(39.1 \%)$ & 1.00 \\
Aortic valve lesion & & & \\
$\quad$ Stenosis & $43(82.7 \%)$ & $38(82.6 \%)$ & \\
Regurgitation & $2(3.9 \%)$ & $3(6.5 \%)$ & \\
Mixed & $7(13.4 \%)$ & $5(10.9 \%)$ & .7880 \\
\hline
\end{tabular}

$C E$, Carpentier-Edwards pericardial bioprosthesis; SPV, Toronto Stentless Porcine Valve; $B S A$, body surface area; $N Y H A$, New York Heart Association; $C H F$, congestive heart failure; Diabetes, insulin-dependent or non-insulin-dependent diabetes mellitus; Hypertension, documented history of treatment for hypertension; $C R F$, chronic renal failure; $C C S$, Canadian Cardiovascular Society; $C O P D$, chronic obstructive pulmonary disease; $P V D$, peripheral vascular disease; $C A D$, coronary artery disease.

blinded to patient and prosthesis. Effective valve orifice area, peak and mean pressure gradients, fractional shortening, cardiac output, and left ventricular mass index (LVMI) were calculated by using standard formulae. LVMI was estimated by using the criteria of the Canadian Cardiovascular Society. ${ }^{21}$

Dobutamine stress echocardiographic protocol and measurements. After baseline echocardiographic assessment was completed, dobutamine was infused at incremental doses of $5 \mu \mathrm{g} \cdot \mathrm{kg}^{-1}$. $\min ^{-1}$ every 3 minutes until the target cardiac index was reached (at least twice baseline). If this was not achieved, dobutamine was gradually increased to a maximum dose of $50 \mu \mathrm{g} \cdot \mathrm{kg}^{-1} \cdot \mathrm{min}^{-1}$. The test was terminated in cases of hemodynamic instability or excessive patient symptomatology. The following parameters were recorded at peak cardiac index: peak and mean pressure transvalvular gradients, ejection fraction, cardiac output, and EOA.

Dynamic cardiac magnetic resonance imaging protocol and measurements. A subgroup of randomly selected patients $(\mathrm{CE}, \mathrm{n}=15 ; \mathrm{SPV}, \mathrm{n}=15)$ underwent dynamic cardiac magnetic resonance imaging (MRI) to quantify LV mass and coronary flow reserve. LV function was assessed by using a well-validated cardiac imaging protocol known as steady-state free precession. ${ }^{22} \mathrm{~A}$ stack of $2 \mathrm{D}$ images covering the heart was acquired, and the cardiac borders were semiautomatically traced to calculate the LV mass, stroke volume, and ejection fraction. Annular motion and stiffness were measured by using a time-resolved MRI tagging sequence, ${ }^{23}$ and velocity-sensitive (phase contrast) MRI was used to measure annular motion. ${ }^{24}$ The same velocity-sensitive sequence was also used to quantify disorderly flow conditions distal to the valve in the ascending aorta.

DASI. The DASI is a disease-specific quality-of-life instrument that has been highly correlated with peak oxygen uptake (Spearman correlation coefficient $=0.58){ }^{25}$ This brief, self-administered, 12-item questionnaire is a reliable and valid measure of functional status and exercise capacity. Var- ious spheres of daily activity are assessed, with possible scores ranging from 0 to 58.2 points. The questionnaire was administered to patients at followup, with comparison with scores obtained at 3 and 12 months postoperatively.

Plasma B-type (brain) natriuretic peptide. A positive correlation has previously been established between plasma levels of Btype (brain) natriuretic peptide (BNP), LVMI, and clinical outcome after AVR. ${ }^{26-30}$ After appropriate informed consent was obtained, venous blood for plasma BNP was drawn (along with routine blood work) from patients' antecubital veins. Samples were collected into chilled ethylenediamine tetraacetic acid Vacutainer test tubes, after which plasma separation was performed at $-4{ }^{\circ} \mathrm{C}$. Plasma samples were frozen at -70 ${ }^{\circ} \mathrm{C}$ until assay. BNP was determined by using a commercially available fluorescence immunoassay (Biosite Diagnostics, Inc, San Diego, Calif). Relation of BNP levels to echocardiographic and clinical outcomes was studied.

\section{Data Analysis}

All data were entered and managed in a FoxPro (Microsoft Corp, Seattle, Wash) database and analyzed with SAS software (SAS Institute, Inc, Cary, NC).

Primary outcome. The regression of LVMI as measured with 2D echocardiography (and confirmed with MRI) was the primary outcome in this follow-up study. LV mass regression was calculated by subtracting the mass index at follow-up from the mass index preoperatively. A mixed linear model was used to account for both varying lengths of follow-up and censoring because of death or reoperation.

Secondary outcomes. Secondary end points included transvalvular gradients (both at rest and exercise), EOAs, transvalvular flow profiles, functional outcome (by means of DASI and NYHA classification), and plasma BNP concentrations. Analyses of echocardiographic and dynamic MRI measurements, as well as DASI scores of functional capacity, were undertaken by using a mixed linear model, as above. LV mass was compared across all modalities by using a Pearson correlation coefficient. Plasma BNP measurements were compared between groups with the Student's $t$ test.

Clinical outcomes, such as survival, were determined by means of Kaplan-Meier analyses. The SPV and CE groups were compared with the log-rank test. Similar analyses were performed for freedom from reoperation and nonfatal valve-related events, including structural valve deterioration, reoperation, nonstructural dysfunction, thromboembolism, and endocarditis. Multivariable predictors of the secondary outcomes were determined by using parametric methods (Wiebull function). Relevant risk factors, including demographic and preoperative variables, were entered into the model in addition to valve type (SPV or CE) to determine the effect of valve selection on survival, adjusting for other confounding factors/effect modifiers. Multiple linear regression was performed to identify the role of various preoperative predictors and prosthesis type on the secondary outcomes.

\section{RESULTS}

Ninety-nine patients were initially randomized in this prospective trial. Preoperative clinical characteristics, including age, body surface area, NYHA functional class, hypertension, the presence of coronary artery disease, and LV grade were similar between groups (Table 1). Post hoc assessment of implanted valve frequencies revealed that surgeons were extremely consistent in selecting similar valve sizes for a given annular diameter, regardless of prosthesis type. However, despite an apparent difference in mean implanted valve sizes between groups (based on manufacturer's 
TABLE 2. Characteristics of patients available for echocardiographic follow-up

\begin{tabular}{lccr}
\hline & CE $(\mathbf{n}=\mathbf{1 7})$ & SPV $(\mathbf{n}=\mathbf{2 1})$ & $\boldsymbol{P}$ value \\
\hline Age $(\mathrm{y})$ & $75.9 \pm 9.2$ & $79.5 \pm 5.9$ & .22 \\
Age $>70$ y & $12(71 \%)$ & $14(67 \%)$ & .65 \\
Female sex & $7(41 \%)$ & $3(14 \%)$ & .14 \\
CHF & 0 & $2(9 \%)$ & .50 \\
Diabetes & 0 & $1(5 \%)$ & 1.00 \\
Hypertension & $7(41 \%)$ & $12(48 \%)$ & .65 \\
CRF & 0 & 0 & 1.00 \\
CCS class III-IV & 0 & 0 & 1.00 \\
COPD & $1(6 \%)$ & $2(9 \%)$ & .76 \\
PVD & 0 & $2(9 \%)$ & .50 \\
Ejection fraction, n $(\%)$ & & & \\
$>60 \%$ & $14(82)$ & $15(71)$ & \\
$40 \%-59 \%$ & $2(12)$ & $5(24)$ & \\
$20 \%-39 \%$ & $1(6)$ & $1(5)$ & \\
$<20 \%$ & $0(0)$ & $0(0)$ & .46 \\
NYHA class, n $(\%)$ & & & \\
I & $14(82)$ & $15(71)$ & \\
II & $3(18)$ & $6(29)$ & \\
III & $0(0)$ & $0(0)$ & \\
IV & $0(0)$ & $0(0)$ & .11 \\
\hline CE & 0 C $\%$. &
\end{tabular}

$C E$, Carpentier-Edwards pericardial bioprosthesis; SPV, Toronto Stentless Porcine Valve; $C H F$, congestive heart failure; Diabetes, insulin-dependent or non-insulin-dependent diabetes mellitus; Hypertension, documented history of treatment for hypertension; $C R F$, chronic renal failure; $C C S$, Canadian Cardiovascular Society; $C O P D$, chronic obstructive pulmonary disease; $P V D$, peripheral vascular disease; NYHA, New York Heart Association functional class.

labeled valve size: $\mathrm{CE}, 22.9 \pm 2.0 \mathrm{~mm}$; SPV, $26.3 \pm 2.0$ $\mathrm{mm} ; P=.0001$ ), actual valvular internal diameters were not significantly different in the 2 groups (CE, $21.9 \pm 2.0$ $\mathrm{mm}$; SPV, $22.3 \pm 2.0 \mathrm{~mm} ; P=.286)$. Furthermore, the incidence of patient-prosthesis mismatch (EOA/body surface area, $<0.75 \mathrm{~cm}^{2} / \mathrm{m}^{2}$ ) was not significantly different between groups (CE, $11 \%$; SPV, $13 \% ; P=1.00$ ).

Perioperative morbidity and mortality were not different between groups, with 4 early deaths recorded. Of the 2 early deaths in the CE group, one was related to stroke, and the other was related to myocardial infarction after injury to the right coronary artery. Cause of death in the patients with SPVs was endocarditis, leading to multisystem organ failure in 1 patient and brainstem infarction in another. Mortality at late follow-up was similar in the 2 groups, with $11(20.8 \%)$ recorded deaths in the CE group and $8(17.3 \%)$ recorded deaths in the SPV group $(P=.49)$ at 12 years.

Patient characteristics at follow-up are presented in Table 2. Late clinical follow-up was $82 \%$ complete at a mean of 10.3 years postoperatively (range, 7.5-12.2 years). Mean age at follow-up was $75.9 \pm 9.2$ years in the CE group and $79.5 \pm 5.9$ years in the SPV group. Nonvalve-related variables that might have adversely affected overall patient well-being or functional capacity were not different between groups (Table 2).
Thirty-eight patients (CE group, $\mathrm{n}=17$; SPV group, $\mathrm{n}=21$ ) were available for late echocardiographic evaluation at a mean of 9.3 years postoperatively (range, 7.5-11.1 yrs). Table 3 displays the early and late echocardiographic outcomes only in those patients available for both early and long-term follow-up. Comparison with early outcomes previously published for the entire group demonstrated similar trends out to 1 year postoperatively; however, there were significant differences at 9 years. ${ }^{18}$

EOAs increased significantly in both groups during the first postoperative year, with initial improvement occurring primarily during the first 3 months after surgical intervention (effect of time, $P=.0001$ ). No differences in EOAs were demonstrated between groups at 3 months $(P=.392)$ or 12 months $(P=.606)$ postoperatively. The mean EOA at 1 year was $1.88 \pm 0.56 \mathrm{~cm}^{2}$ in the CE group and $2.02 \pm$ $0.76 \mathrm{~cm}^{2}$ in the SPV group $(P=.606)$. However, whereas EOAs decreased significantly in the CE group thereafter, EOAs remained stable in the SPV group with time. At 9 years, mean EOA was $1.49 \pm 0.59 \mathrm{~cm}^{2}$ in the CE group and $2.00 \pm 0.53 \mathrm{~cm}^{2}$ in the SPV group $(P=.002)$. Overall, no significant effects were demonstrated for the treatmentby-time interaction (group $\times$ time effect, $P=.0 .331$ ). Furthermore, echocardiographers were unable to identify any consistent anatomic or qualitative differences between valves to account for the observed quantitative differences in EOAs.

Mean and peak transvalvular gradients decreased significantly over the first year in both groups, once again with most of the initial improvement occurring during the first 3 postoperative months (effect of time, $P=$ .0001 in both groups). Although mean and peak gradients were lower in patients with SPVs at 3 months (mean, $P=.035$; peak, $P=.022$ ), no differences in gradients were noted at 1 year (mean, $P=.240$; peak, $P=.197)$.

After 1 year, mean and peak transvalvular gradients increased in both groups, although to a greater degree in the $\mathrm{CE}$ group. At 9 years, mean gradients were $10.86 \pm 3.7$ $\mathrm{mm} \mathrm{Hg}$ in the CE group and $7.47 \pm 4.3 \mathrm{~mm} \mathrm{Hg}$ in the SPV group $(P=.027)$, whereas peak gradients were 20.38 $\pm 6.5 \mathrm{~mm} \mathrm{Hg}$ in the CE group and $14.59 \pm 7.1 \mathrm{~mm} \mathrm{Hg}$ in the SPV group $(P=.025)$. Such differences were magnified with dobutamine administration (mean: $\mathrm{CE}, 22.7 \pm 6.1 \mathrm{~mm}$ $\mathrm{Hg}$; SPV, $15.3 \pm 8.4 \mathrm{~mm} \mathrm{Hg} ; P=.008$; peak: CE, $48.1 \pm$ $11.8 \mathrm{~mm} \mathrm{Hg}$; SPV, $30.8 \pm 17.7 \mathrm{~mm} \mathrm{Hg} ; P=.001)$. Overall, no significant effects were demonstrated for the treatmentby-time interaction (group $\times$ time effect: mean, $P=.900$; peak, $P=.456$ ).

Measures of LV function were similar between groups, improving in all patients over time. At 9 years, $94 \%$ of patients in the CE group and $95 \%$ of patients in the SPV group exhibited ejection fractions of $40 \%$ or greater. Ejection fractions normalized in both groups after dobutamine 
TABLE 3. Echocardiographic parameters and DASI scores in follow-up patients

\begin{tabular}{|c|c|c|c|c|c|c|}
\hline & Preoperative & $3 \mathrm{mo}$ & $1 \mathbf{y}$ & $9 y$ & $P$ value $(1$ y vs 10 y) & $P$ value $($ group $\times$ time $)$ \\
\hline \multicolumn{7}{|l|}{$\mathrm{EOA}\left(\mathrm{cm}^{2}\right)$} \\
\hline $\mathrm{CE}$ & $0.754 \pm 0.228$ & $1.53 \pm 0.48$ & $1.88 \pm 0.56$ & $1.492 \pm 0.599$ & .040 & \\
\hline SPV & $0.775 \pm 0.20$ & $1.75 \pm 0.84$ & $2.02 \pm 0.76$ & $2.000 \pm 0.532$ & .933 & 331 \\
\hline$P$ value & .791 & .392 & .606 & .002 & & \\
\hline \multicolumn{7}{|c|}{ Mean gradient (mm Hg) } \\
\hline $\mathrm{CE}$ & $54.60 \pm 16.3$ & $10.39 \pm 4.8$ & $7.06 \pm 3.7$ & $10.86 \pm 3.7$ & .015 & \\
\hline SPV & $53.56 \pm 12.3$ & $6.96 \pm 3.1$ & $5.59 \pm 2.9$ & $7.47 \pm 4.3$ & .145 & 900 \\
\hline$P$ value & .850 & .035 & .240 & .027 & & \\
\hline \multicolumn{7}{|c|}{ Peak gradient (mm Hg) } \\
\hline $\mathrm{CE}$ & $84.04 \pm 23.8$ & $18.16 \pm 7.8$ & $12.70 \pm 6.4$ & $20.36 \pm 6.27$ & .005 & \\
\hline SPV & $88.72 \pm 30.9$ & $12.25 \pm 5.0$ & $9.92 \pm 4.8$ & $14.59 \pm 7.14$ & .032 & .456 \\
\hline$P$ value & .640 & .022 & .197 & .025 & & \\
\hline \multicolumn{7}{|c|}{ Fractional shortening $(\%)$} \\
\hline $\mathrm{CE}$ & $38.42 \pm 10.6$ & $33.20 \pm 7.8$ & $39.35 \pm 7.6$ & $27.07 \pm 9.7$ & .023 & \\
\hline SPV & $33.61 \pm 9.2$ & $35.85 \pm 12.1$ & $40.70 \pm 6.1$ & $28.65 \pm 10.3$ & $<.001$ & .212 \\
\hline$P$ value & .214 & .509 & .615 & .667 & & \\
\hline \multicolumn{7}{|c|}{$\operatorname{LVMI}\left(\mathrm{g} / \mathrm{m}^{2}\right)$} \\
\hline $\mathrm{CE}$ & $133.70 \pm 29.4$ & $119.58 \pm 34.8$ & $115.36 \pm 35.9$ & $111.22 \pm 21.4$ & .762 & \\
\hline SPV & $128.64 \pm 45.4$ & $114.68 \pm 23.8$ & $109.99 \pm 5.25$ & $102.60 \pm 22.8$ & .395 & .619 \\
\hline$P$ value & .711 & .652 & .639 & .369 & & \\
\hline \multicolumn{7}{|c|}{ LVIDd (mm) } \\
\hline $\mathrm{CE}$ & $42.92 \pm 9.2$ & $43.50 \pm 6.4$ & $43.92 \pm 6.7$ & $40.79 \pm 12.0$ & .431 & \\
\hline SPV & $48.88 \pm 6.8$ & $47.86 \pm 5.8$ & $46.82 \pm 6.1$ & $45.29 \pm 8.1$ & .536 & .742 \\
\hline$P$ value & .050 & .069 & .235 & .222 & & \\
\hline \multicolumn{7}{|c|}{ LVIDs (mm) } \\
\hline $\mathrm{CE}$ & $27.58 \pm 9.3$ & $28.69 \pm 6.6$ & $26.36 \pm 5.9$ & $32.43 \pm 8.6$ & .057 & \\
\hline SPV & $33.25 \pm 8.6$ & $30.50 \pm 6.2$ & $27.63 \pm 4.9$ & $32.5 \pm 9.6$ & & .319 \\
\hline$P$ value & .108 & .470 & .551 & .976 & .075 & \\
\hline \multicolumn{7}{|l|}{ IVSd (mm) } \\
\hline $\mathrm{CE}$ & $15.00 \pm 2.8$ & $14.42 \pm 3.2$ & $13.50 \pm 3.1$ & $14.1 \pm 4.5$ & .670 & \\
\hline SPV & $13.82 \pm 2.5$ & $12.86 \pm 2.4$ & $12.59 \pm 1.97$ & $11.9 \pm 1.5$ & .292 & .845 \\
\hline$P$ value & .240 & .155 & .337 & .089 & & \\
\hline \multicolumn{7}{|c|}{ DSE mean gradient $(\mathrm{mm} \mathrm{Hg})$} \\
\hline $\mathrm{CE}$ & & & & $22.7 \pm 6.1$ & & \\
\hline SPV & & & & $15.3 \pm 8.4$ & & \\
\hline$P$ value & & & & .008 & & \\
\hline \multicolumn{7}{|c|}{ DSE peak gradient $(\mathrm{mm} \mathrm{Hg})$} \\
\hline $\mathrm{CE}$ & & & & $48.1 \pm 11.8$ & & \\
\hline SPV & & & & $30.8 \pm 17.7$ & & \\
\hline$P$ value & & & & .001 & & \\
\hline \multicolumn{7}{|l|}{ DASI (mm) } \\
\hline $\mathrm{CE}$ & $13.91 \pm 8.3$ & $24.01 \pm 14.3$ & $24.93 \pm 20.0$ & $25.00 \pm 19.5$ & .999 & \\
\hline SPV & $14.12 \pm 10.1$ & $20.53 \pm 12.0$ & $28.35 \pm 6.4$ & $19.86 \pm 12.0$ & .004 & .471 \\
\hline$P$ value & .953 & .466 & .586 & .423 & & \\
\hline
\end{tabular}

DASI, Duke Activity Status Index; EOA, effective orifice area; $C E$, Carpentier-Edwards pericardial bioprosthesis; $S P V$, Toronto Stentless Porcine Valve; $L V M I$, left ventricular mass indexed on body surface area; $L V I D d$, left ventricular internal dimension at end-diastole; $L V I D s$, left ventricular internal dimension at end-systole; IVSd, interventricular septal thickness at end-diastole; $P W T d$, posterior wall thickness at end-diastole; DSE, dobutamine stress echocardiography.

administration, with $100 \%$ of the patients in both groups exhibiting ejection fractions of greater than $60 \%$. Overall, no evidence of localized or global wall motion abnormality was noted with dobutamine administration. Percentages of fractional shortening, although similar in the 2 groups at 9 years, decreased over time, with significant improvement after dobutamine administration.
LV mass indexed on body surface area (LVMI) was similar in the 2 groups at baseline $\left(\mathrm{CE}, 133 \mathrm{~g} / \mathrm{m}^{2} ; \mathrm{SPV}, 128 \mathrm{~g} / \mathrm{m}^{2}\right.$; $P=.711)$. Mass regression continued in both groups out to 9 years, with most of the early effects occurring during the first 3 postoperative months (effect of time, $P=.0001$ in both groups). However, no differences in mass regression were shown between groups at either 3 months $(P=.652)$ or 12 


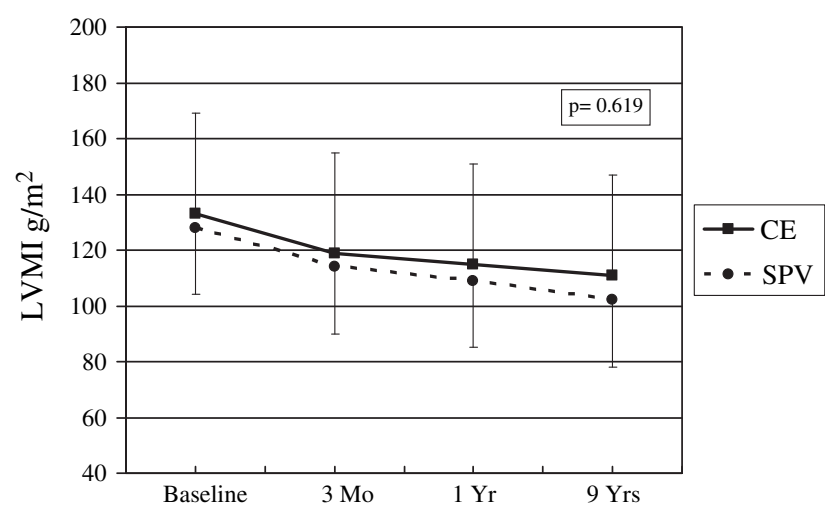

FIGURE 1. Regression of left ventricular mass index (LVMI). CE, Carpentier-Edwards stented valve; $S P V$, Toronto Stentless Porcine Valve.

months $(P=.639)$ postoperatively. Neither valve had a significant early size-related advantage in patients with small $(\leq 23 \mathrm{~mm}$ ) aortic annuli (LV mass regression for annuli $\leq 23 \mathrm{~mm}$ : CE, $23.3 \mathrm{~g} / \mathrm{m}^{2}$; SPV, $\left.24.2 \mathrm{~g} / \mathrm{m}^{2} ; P=.6381\right)$.

After 1 year, ventricular mass continued to regress slightly in both groups, although not to a significant degree. At 9 years, $\mathrm{LV}$ mass regression was $22.48 \mathrm{~g} / \mathrm{m}^{2}$ in the CE group and $26.04 \mathrm{~g} / \mathrm{m}^{2}$ in the SPV group $(P=.393)$. Overall, no significant effects were demonstrated for the treatment-by-time interaction (group $\times$ time effect, $P=.619$; Figure 1).

Cardiac MRI confirmed the echocardiographic LV mass findings. At 9 years, MRI-generated LVMI was $100.13 \pm$ $38.3 \mathrm{~g} / \mathrm{m}_{2}$ in the CE group and $103.22 \pm 29.0 \mathrm{gm} / \mathrm{m}^{2}$ in the SPV group $(P=.86)$. Among patients who underwent both echocardiographic and MRI assessments, measures of LV mass were found to be highly correlative $(r=0.91$, $P=.001)$.

Plasma BNP concentrations were similar in the 2 groups, although highly variable (CE, $98.11 \pm 82.6 \mathrm{pmol} / \mathrm{L} ; \mathrm{SPV}$, $106.30 \pm 96.1 \mathrm{pmol} / \mathrm{L})$. Overall, plasma BNP concentrations were found to correlate strongly with LVMI ( $r=$ $0.66, P=.003)$. No correlation was found with mean/peak gradients or DASI/NYHA scores. Patients with significant aortic insufficiency (AI) at follow-up were more likely to have BNP concentrations in excess of $200 \mathrm{pmol} / \mathrm{L}$.

DASI scores improved significantly over the first year in both groups $(P=.0001)$. At 1 year, patients with CEs scored $24.93 \pm 10.0$, whereas patients with SPVs scored $28.35 \pm$ $6.4(P=.586)$. After 1 year, DASI scores of functional status remained relatively stable in patients with CEs while decreasing in patients with SPVs, although the difference was not statistically significant $(\mathrm{CE}, 25.00 \pm 9.5$; SPV, $19.86 \pm 12.0 ; P=.423)$. Overall, no significant effects were demonstrated for the treatment-by-time interaction (group $\times$ time, $P=.471$; Table 3 ).

A similar trend was demonstrated with respect to NYHA functional status, which improved significantly over time in

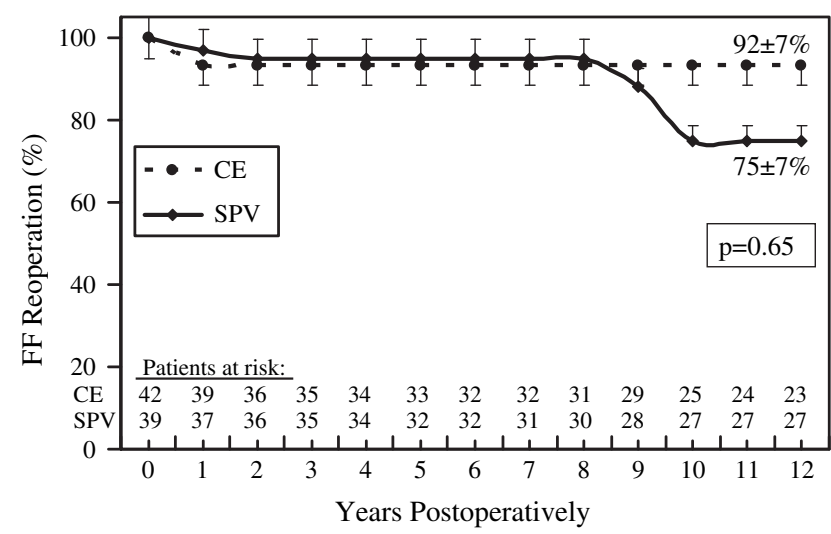

FIGURE 2. Actuarial freedom from reoperation ( $F F$ Reoperation). $C E$, Carpentier-Edwards stented valve; $S P V$, Toronto Stentless Porcine Valve.

both groups. At 9 years, $100 \%$ of patients in both groups were in NYHA functional classes I or II (Table 2).

Aortic root dilatation $(>3.5 \mathrm{~cm})$ was observed in 2 patients $(\mathrm{CE}, 1 ; \mathrm{SPV}, 1)$ at follow-up. In the CE group 6 patients exhibited mild AI, with 1 patient exhibiting mildto-moderate AI (aortic root diameter, $3.4 \mathrm{~cm}$ ). In the SPV group 4 patients exhibited mild AI, 2 patients exhibited mild-to-moderate AI (aortic root diameter, 3.4 and $3.5 \mathrm{~cm}$, respectively), and 1 patient exhibited moderate-to-severe AI (aortic root diameter, $3.8 \mathrm{~cm}$ ).

Actuarial freedom from reoperation was similar in both groups out to 9 years; however, it dropped off in stentless patients thereafter (CE, 92\% $\pm 5 \%$; SPV, $75 \% \pm 5 \%$; $P=.65$; Figure 2). Among patients requiring reoperation, 5 had documented structural valve dysfunction. One patient in the $\mathrm{CE}$ group underwent reoperation for prosthetic valve endocarditis, with significant AI documented before infection, whereas 4 patients in the SPV group required reoperation for severe valvular dysfunction, with resultant stenosis or regurgitation. Findings during surgical intervention included leaflet vegetations and tears in the patient with a CE and leaflet calcifications and tears in the patients with SPVs. Two patients in the SPV group required reoperation for nonstructural valve dysfunction. Findings in these patients included leaflet tears associated with dilatation of the sinotubular junction. All patients survived reoperation, with no significant perioperative complications.

Actuarial freedom from valve-related morbidity was $82 \% \pm 5 \%$ in the $\mathrm{CE}$ group and $55 \% \pm 5 \%$ in the SPV group $(P=.05$, Figure 3$)$. Valve-related events included 1 patient with endocarditis and 3 patients with thromboembolic episodes in the CE group versus 2 patients with endocarditis and 5 patients with thromboembolic episodes in the SPV group. Finally, actuarial survival (freedom from all-cause mortality) was $35 \% \pm$ $7 \%$ in the CE group and $52 \% \pm 7 \%$ in the SPV group $(P=.37$, Figure 4$)$. 


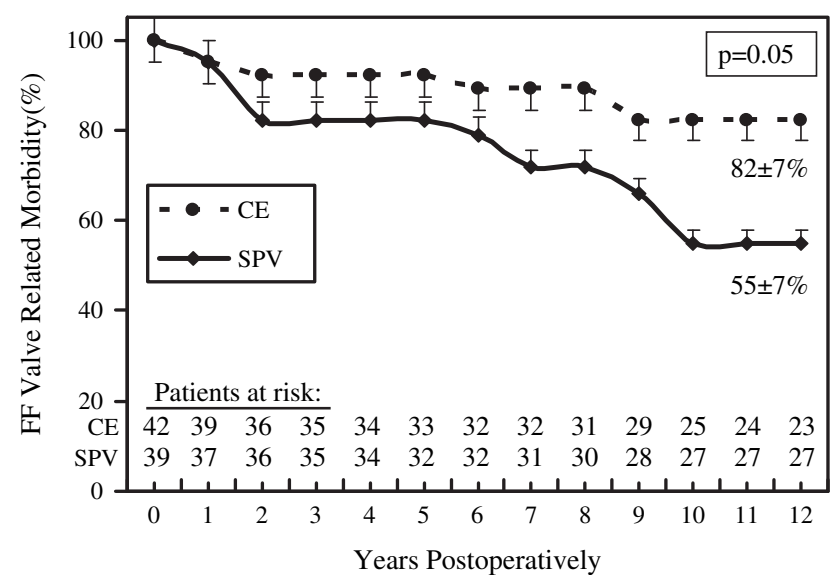

FIGURE 3. Actuarial freedom from valve-related morbidity ( $F F$ Valve Related Morbidity). CE, Carpentier-Edwards stented valve; SPV, Toronto Stentless Porcine Valve.

\section{DISCUSSION}

The suggested hemodynamic superiority of stentless valves has been well documented in various reports over the past decade. Unfortunately, most studies are retrospective, some from trial databases, others case matched, and only a few prospectively randomized with attention to true annular and valvular dimensions. Even among published randomized trials, no unified message has evolved. In a recent trial by Ali and colleagues, ${ }^{31} 161$ patients were randomized to receive either the Edwards Prima stentless bioprosthesis or the Carpentier-Edwards Perimount stented bioprosthesis. Although the mean implanted valve size was larger in the stentless group, at 8 weeks postoperatively, no differences in transvalvular gradients or ventricular mass were noted between groups. Similarly, in an article by Chambers and coworkers, ${ }^{14}$ among 160 patients randomized to receive either the Edwards Perimount stented valve or the SPV, no significant differences were demonstrated in hemodynamic function or clinical events up to 5 years postoperatively. Conversely, in a trial by Perez de Arenaza and assoociates $^{32}$ in which 191 patients were randomized to stented or stentless valves, significant benefits in both indexed EOA and peak flow velocity were demonstrated in the stentless valve group. Finally, in a study by Dunning and associates, ${ }^{33}$ among 60 patients randomized to either the Sorin Freedom stentless or the Sorin More stented bioprostheses, lower peak gradients and greater EOAs were shown in the stentless group. These differences were also associated with earlier regression of LV hypertrophy.

The above shows the great disparity and limitation inherent in contemporary randomized trials of stentless versus stented valves. Perhaps the closest to some form of consensus has come from 2 recent publications. A meta-analysis of 10 published randomized trials involving a total of 919 patients performed by Kunadian and colleagues ${ }^{16}$ concluded that stentless aortic valves provide reduced aortic gradients

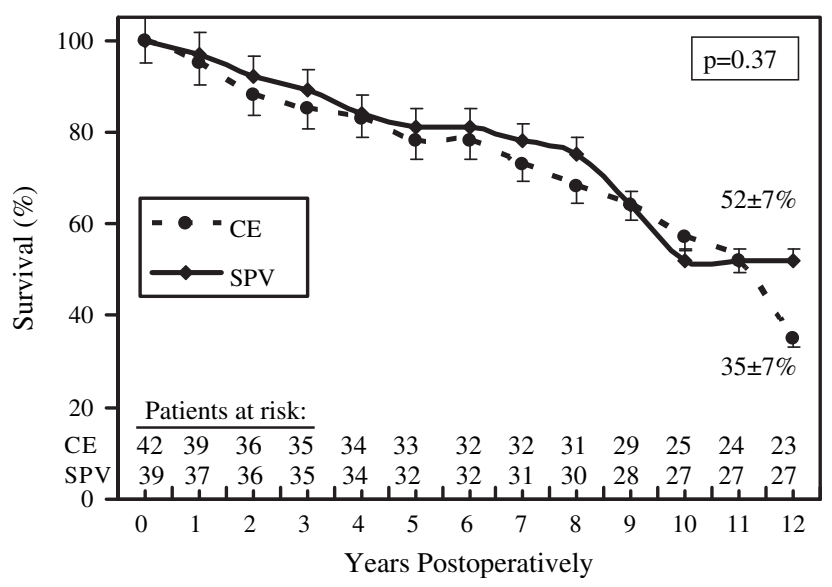

FIGURE 4. Actuarial survival. $C E$, Carpentier-Edwards stented valve; $S P V$, Toronto Stentless Porcine Valve.

and an improved EOA index at the expense of a 23-minute longer crossclamp time and a 29-minute longer bypass time. Although LV mass regression in patients receiving stentless valves was superior at 6 months, ultimate regression of LV mass at 1 year postoperatively was not different between groups. Similarly, a meta-analysis by Raja and coworkers ${ }^{34}$ concluded superior early hemodynamic performance of stentless valves. However, the effect on LV mass regression was found to be similar for both stented and stentless valve types. The authors concluded that this finding might have been due to improved performance of second- and thirdgeneration stented valves.

Notwithstanding such reports, the above findings raise a number of important questions. First, are previously published negative studies limited by their relatively short duration of follow-up, such that late advantages in hemodynamics, LV mass, and/or clinical outcome are unapparent? Would seemingly minor differences in hemodynamics be augmented under conditions of stress? With respect to positive studies, are the early reported hemodynamic benefits of stentless valves maintained long-term? Do such hemodynamic differences translate into improvements in functional status, clinical outcome, or both?

To date, the longest documented follow-up of randomized patients is a midterm assessment performed by Lehmann and associates $^{35}$ involving patients assigned to receive either stentless (SPV or Freestyle) or stented (CE) valves. At a mean of 6.9 years postoperatively, patients in the stentless group demonstrated lower transvalvular flow velocities and improved survival, albeit with no correlation to transvalvular gradients.

The current study was designed as a long-term follow-up of patients previously randomized in our original trial of stentless versus stented valves. Although no differences in hemodynamic or clinical outcomes were demonstrated at 1 
year postoperatively, at 9 years' follow-up, the SPV exhibited superior hemodynamic performance.

Most currently available bioprostheses have acceptable hemodynamic indices at rest. However, as cardiac output increases (ie, with exercise), valvular flow profiles and, in particular, transvalvular gradients might change accordingly. ${ }^{36-38}$ In light of the aforementioned, we chose to evaluate our patients using dobutamine stress echocardiographic analysis to simulate conditions of exercise. In doing so, the differences between groups were magnified, such that gradients increased more significantly in the $\mathrm{CE}$ group versus those in the SPV group.

Although such findings appear significant at first glance, the question remains: do such hemodynamic differences translate into differences in LV mass or functional/clinical outcome?

Ventricular hypertrophy has long been known to correlate strongly with poor long-term outcomes. ${ }^{39-41}$ Although ventricular mass regression can be detected as early as 1 week after AVR, regression has been documented well into the fifth postoperative year. ${ }^{42}$

In the current patient population, indexed LV mass regressed significantly in both groups over time, with most of the early effect occurring during the first 3 postoperative months. However, no differences in mass regression were found between groups either at 1 or 9 years postoperatively. These findings were confirmed through MRI studies and were further supported by plasma BNP measurements, which correlated highly with measurements of ventricular mass. This finding is of particular interest in light of similar reports indicating a correlation with transvalvular gradients and long-term survival. ${ }^{43-45}$ Although $50 \%$ of patients in either group were hypertensives, all such patients were successfully managed medically, as confirmed on trial enrollment and during follow-up appointments, thus limiting the potential effect on mass regression.

Functional outcomes in this study were determined by using well-described methods. Because the risk of cardiac morbidity and mortality associated with stress testing in patients with critical aortic stenosis precludes its preoperative use, we used the DASI score to evaluate functional capacity. As a clinical outcome proxy for exercise capacity, DASI scores permitted the evaluation of functional status and quality of life with a comparison with NYHA status. By using such methods, no differences in functional outcome were demonstrated between groups.

Similarly, although our study was underpowered for the detection of differences in mortality, no obvious survival differences were noted between groups. Such findings were in keeping with those reported by Lehmann and colleagues $^{35}$ in their midterm follow-up of randomized patients receiving stentless devices, in whom hemodynamic differences did not correlate with clinical or functional outcomes. Although survival differences were noted between groups, such differences were not found to be valve related and did not correlate with transvalvular gradients.

Yet additional benefits have been attributed to stentless valves. One such benefit is that of improved coronary flow reserve, possibly caused by reduced turbulence downstream to a stentless valve during systole and improved backflow during diastole. ${ }^{44-48}$ Although an attempt was made to measure coronary flow in the current study by using velocity-encoded MRI, results were highly variable and thus uninterpretable. Nonetheless, with dobutamine administration, ventricular function normalized in all patients with no demonstrable wall motion abnormalities, indicative of normal or nearnormal coronary perfusion in the 2 groups.

Another supposed advantage of stentless valves might be that of superior durability. The inherent flexibility of a stentless valve theoretically takes advantage of the dynamic nature of the aortic annulus, which might vary considerably during the cardiac cycle. ${ }^{49}$ Implantation of a stentless valve within the native aortic root might thus facilitate normal leaflet motion during systole, with a dampening of mechanical stresses and turbulence during diastole. This, in turn, might result in enhanced durability over time with fewer valvular complications at follow-up. ${ }^{50}$

With dynamic MRI assessment, we were unable to demonstrate any significant changes in annular dimension between systole and diastole in either group. This might indicate annular fixation with prosthetic valvular replacement, regardless of valve type. Such findings are in keeping with a previously published report by Kazui and associates, ${ }^{51}$ who evaluated the motion of the aortic root in healthy volunteers using multidetector computed tomographic analysis. Although in the normal aortic root no part of the aortic annulus changed length during the cardiac cycle, the commissural regions were found to move outward during the systolic phase. This finding might be important in the selection of stentless valve implantation technique because dynamic changes in the aortic root might place undue stress on the leaflets of stentless valves implanted by using the subcoronary method.

Irrespective of annular motion, subcoronary stentless valve implantation creates an intimate relationship between aortic dimension and valvular dynamics, which might affect valvular durability. In the current study, valvular insufficiency in patients receiving stentless valves seemed to be related to changes in aortic root diameter. This finding was consistent with reports previously published by our group and others documenting an increased prevalence of prosthetic nonstructural valve dysfunction in patients receiving SPVs when there is dilatation of the sinotubular junction. ${ }^{52,53}$

Such limitations along with the variable hemodynamic benefits of subcoronary implants have prompted some surgeons to adopt a policy of full root replacement for isolated aortic valve disease. However, although improved hemodynamic indices and outcomes have been reported, ${ }^{54,55}$ such 
a technique might introduce significant perioperative risks by complicating an otherwise simple operation. ${ }^{56}$

In the current study freedom from reoperation was similar between groups up to 9 years postoperatively. Thereafter, reoperation was more prevalent in patients receiving SPVs. Although in these cases the reoperative courses were uncomplicated, it must be noted that reoperation for stentless valve explantation has generally been found to be somewhat more complicated than that for stented valve explantation and in some cases has been shown to be associated with an increased risk of death. ${ }^{55}$

\section{LIMITATIONS}

Although our original study was randomized in nature, patient numbers were too small to enable any definitive conclusions regarding group-related differences in long-term mortality or clinical outcome. Furthermore, the current study does not take into account newer generations of stented valvular prostheses and might not be generalizeable to patients who have undergone AVR with other types of stentless valves. Finally, this study did not address potential advantages of one valve type over another in cases of abnormal ventricular function.

\section{CONCLUSIONS}

In conclusion, our findings reaffirm the need for long-term follow-up to evaluate valve-related outcomes. With regard to the current study, although short-term follow-up did not show any differences between stentless and stented valves, with longer-term follow-up, stentless valves were found to outperform their stented counterparts, both at rest and with exercise. However, such improvements did not translate into functional or clinical benefit up to 12 years after implantation and did not affect durability or LV mass regression. In light of these and similar reports, our current practice is to use stentless valves only when full root replacement with a bioprosthesis is indicated.

These findings raise interesting questions with respect to the true impact of hemodynamic differences between valve types. Although EOAs and gradients are crucial in evaluating valve function, patient responses vary, and clinically significant thresholds have yet to be conclusively identified. That being the case, in assessing the benefits of a particular valve design, the goal should be a comparison of clinical outcomes, such as survival, freedom from valve-related morbidity, and functional capacity rather than EOAs, gradients, and patient-prosthesis mismatch.

Finally, both stented and stentless designs were found to be suitable options for AVR. Nonetheless, in selecting a stentless valve, surgeons must evaluate any potential benefits of stentless design against the risks of longer procedural times and more complex reoperations, especially in the face of continued improvements in stented design.

\section{References}

1. Lund O, Bland M. Risk-corrected impact of mechanical versus bioprosthetic valves on long-term mortality after aortic valve replacement. J Thorac Cardiovasc Surg. 2006;132:20-6.

2. Roberts WC, Ko JM, Filardo G, et al. Valve structure and survival in quadragenarians having aortic valve replacement for aortic stenosis ( $H$-aortic regurgitation) with versus without coronary artery bypass grafting at a single US medical center (1993 to 2005). Am J Cardiol. 2007;100:1683-90.

3. Le Tourneau T, Marechaux S, Vincentelli A, et al. Cardiovascular risk factors as predictors of early and late survival after bioprosthetic valve replacement for aortic stenosis. J Heart Valve Dis. 2007; 16:483-8.

4. Ruel M, Chan V, Bédard P, et al. Very long-term survival implications of heart valve replacement with tissue versus mechanical prostheses in adults $<60$ years of age. Circulation. 2007;116(suppl):I294-300.

5. Auriemma S, D'Onofrio A, Brunelli M, et al. Long-term results of aortic valve replacement with Edwards Prima Plus stentless bioprosthesis: eleven years' follow-up. J Heart Valve Dis. 2006;15:691-5.

6. Naslafkih A, François S, Fix JM, Khoury A. Aortic valve replacement and longterm prognosis. J Insur Med. 2006;38:126-35.

7. Rizzoli G, Mirone S, Ius P, et al. Fifteen-year results with the Hancock II valve: a multicenter experience. J Thorac Cardiovasc Surg. 2006;132:602-9.

8. Kvidal P, Bergström R, Hörte LG, Ståhle E. Observed and relative survival after aortic valve replacement. J Am Coll Cardiol. 2000;35:747-56.

9. David TE, Pollick C, Bos J. Aortic valve replacement with the stentless porcine aortic bioprosthesis. J Thorac Cardiovasc Surg. 1990;99:113-8.

10. Jin XY, Gibson DG, Yacoub MH, Pepper JR. Perioperative assessment of aortic homograft, Toronto Stentless Valve, and stented valve in the aortic position. Ann Thorac Surg. 1995;60(suppl):S395-401.

11. Sidiropoulos A, Hotz H, Tschesnow J, Konertz W. Stentless porcine bioprosthesis for all types of aortic root pathology. Eur J Cardiothorac Surg. 1997;11:917-21.

12. Westaby S. Aortic valve replacement with the Freestyle stentless xenograft. Ann Thorac Surg. 1995;60(suppl):S422-7.

13. Pillai R, Spriggings D, Amarasena N, et al. Stentless aortic bioprosthesis? The way forward: early experience with the Edwards valve. Ann Thorac Surg. 1993;56:88-91.

14. Chambers JB, Rimington HM, Hodson F, Rajani R, Blauth CI. The subcoronary Toronto stentless versus supra-annular Perimount stented replacement aortic valve: early clinical and hemodynamic results of a randomized comparison in 160 patients. $J$ Thorac Cardiovasc Surg. 2006;131. 878-2.

15. Nessmith MG, Fukuta H, Brucks S, Little WC. Usefulness of an elevated B-type natriuretic peptide in predicting survival in patients with aortic stenosis treated without surgery. Am J Cardiol. 2005;96:1445-8.

16. Kunadian B, Vijayalakshmi K, Thornley, et al. Meta-analysis of valve hemodynamics and left ventricular mass regression for stentless verus stented aortic valves. Ann Thorac Surg. 2007;84:73-8.

17. Kallikourdis A, Jacob S. Is a stentless aortic valve superior to conventional bioprosthetic valves for aortic valve replacement? Interact Cardiovasc Thorac Surg. 2007;6:665-72.

18. Cohen G, Christakis GT, Joyner CD, et al. Are stentless valves hemodynamically superior to stented valves? A prospective randomized trial. Ann Thorac Surg. 2002;73:767-75.

19. Akins CW, Miller DC, Turina MI, et al. Guidelines for reporting mortality and morbidity after cardiac valve interventions. J Thorac Cardiovasc Surg. 2008; 135:732-8.

20. Edmunds LH, Clark RE, Cohn LH, Grunkemeier GL, Miller CD, Weisel RD. Ad Hoc Liason Committee for Standardizing Definitions of Prosthetic Heart Valve Morbidity of the American Association for Thoracic Surgery and the Society of Thoracic Surgeons. J Thorac Cardiovasc Surg. 1996;112:708-11.

21. Task Force of the Echocardiography Section of the Canadian Cardiovascular Society and the Canadian Hypertension Society. Guidelines from the Canadian Cardiovascular Society and the Canadian Hypertension Society on the echocardiographic determination of left ventricular mass. Can J Cardiol. 1995; 11:391-5.

22. Lee VS, Resnick D, Bundy JM, Simonetti OP, Lee P, Weinreb JC. Cardiac function: MR evaluation in one breath hold with real-time true fast imaging with steady-state precession. Radiology. 2002;222:835-42.

23. Bolster BD, McVeigh ER, Zerhouni EA. Myocardial tagging in polar coordinates with use of striped tags. Radiology. 1990;177:769-72.

24. Zhu Y, Drangova M, Pelc NJ. Estimation of deformatoin gradient and strain from cine-PC velocity data. IEEE Trans Med Imaging. 1997;16:840-51. 
25. Hlatky MA, Boineau RE, Higginbothan MB, et al. A brief self-administered questionnaire to determine functional capacity (the Duke Activity Status Index). Am J Cardiol. 1989;64:651-64.

26. Almeida SS, Azevedo A, Castro A, et al. B-type natriuretic peptide is related to left ventricular mass in hypertensive patients but not in athletes. Cardiology. 2002;98:113-5.

27. Zoccali C, Mallamaci F, Benedetto FA, et al. Cardiac natriuretic peptides are related to left ventricular mass and function and predict mortality in dialysis patients. J Am Soc Nephrol. 2001;12:1508-15.

28. Luchner A, Burnett JC, Jougasaki M, et al. Evaluation of brain natriuretic peptide as marker of left ventricular dysfunction and hypertrophy in the population. J Hypertens. 2000;18:1121-8.

29. McDonagh TA, Robb SD, Murdoch DR, et al. Biochemical detection of left ventricular systolic dysfunction. Lancet. 1998;351:9-13.

30. Bergler-Klein J, Mundigler G, Pibarot P, et al. B-type natriuretic peptide in lowflow, low gradient aortic stenosis: relationship to hemodynamics and clinical outcome: results from the multicenter Truly or Pseudo-Severe Aortic Stenosis (TOPAS) study. Circulation. 2007;115:2848-55

31. Ali A, Halstead JC, Cafferty F, et al. Early clinical and hemodynamic outcomes after stented and stentless aortic valve replacement: results from a randomized controlled trial. Ann Thorac Surg. 2007;83:2162-8.

32. Perez de Arenaza D, Lees B, Flather M, et al. Randomized comparison of stentless versus stented valves for aortic stenosis: effects on left ventricular mass. Circulation. 2005;112:2696-702.

33. Dunning J, Graham RJ, Thambyrajah J, Stewart MJ, Kendall SW, Hunter S. Stentless vs. stented aortic valve bioprostheses: a prospective randomized controlled trial. Eur Heart J. 2007;28:2369-74.

34. Raja SG, Macarthur KJ, Pollock JC. Impact of stentless aortic valves on left ventricular function and hypertrophy: current best available evidence. J Card Surg. 2006;21:313-9.

35. Lehmann S, Walther T, Kempfert J, Leontjev S, Rastan A, Falk V, et al. Stentless versus conventional xenograft aortic valve replacement: midterm results of a prospectively randomized trial. Ann Thorac Surg. 2007;84:467-72.

36. Tatineni S, Barner HB, Pearson AC, Halbe D, Woodruff R, Labovitz AJ. Rest and exercise evaluation of St. Jude Medical and Medtronic-Hall prostheses. Influence of primary lesion, valvular type, valvular size and left ventricular function. Circulation. 1999;80:16-23

37. Silberman S, Shaheen J, Fink D, et al. Comparison of exercise hemodynamics among non-stented aortic bioprostheses, mechanical valves, and normal native aortic valves. J Card Surg. 1998;13:412-6.

38. Zabalgoitia M, Kopek K, Oneschuk L, et al. Use of dobutamine stress echocardiography in assessing mechanical aortic prostheses: comparison with exercise echocardiography. J Heart Valve Dis. 1997;6:253-7.

39. Sullivan JM, Vander Zwaag R, El Zeky F, Ramanathan KB, Mirvis DM. Left ventricular hypertrophy: effect on survival. J Am Coll Cardiol. 1993;22:508-13.

40. Levy D, Anderson KM, Savage DD, Balkus SA, Kannel WB, Castelli WB. Risk of ventricular arrhythmias in left ventricular hypertrophy: the Framingham Heart Study. Am J Cardiol. 1987;60:560-5.

41. Levy D. Clinical significance of left ventricular hypertrophy: insights from the Framingham study. J Cardiovasc Pharmacol. 1991;17(suppl):S1-6.

42. Gelsomino S, Frassani R, Morocutti G, et al. Time course of left ventricular remodeling after stentless aortic valve replacement. Am Heart J. 2001;142:556-62.

43. Gerber IL, Stewart RA, Legget ME, et al. Increased plasma natriuretic peptide levels reflect symptom onset in aortic stenosis. Circulation. 2003;107:1884-90.

44. Talwar S, Downie PF, Squire IB, Davies JE, Barnett DB, Ng LL. Plasma N-terminal pro-BNP and cardiotrophin-1 are elevated in aortic stenosis. Eur J Heart Fail. 2001;3:15-9.

45. Bergler-Klein J, Mundigler G, Pibarot P, et al. B-type natriuretic peptide in low-flow, low-gradient aortic stenosis: relationship to hemodynamics and clinical outcome: results from the Multicenter Truly or Pseudo-Severe Aortic Stenosis (TOPAS) study. Circulation. 2007;115:2848-55

46. Bakhtiary F, Schiemann M, Dzemali O, et al. Stentless bioprostheses improve postoperative coronary flow more than stented prostheses after valve replacement for aortic stenosis. Impact on coronary flow. J Thorac Cardiovasc Surg. 2006;131:883-8.

47. Scherer M, Abdel-Rahman U, Dzermali O, et al. Pathophysiology of coronary artery flow during extracorporeal circulation (ECC), myocardial ischemia and mechanical aortic valve replacement-an experimental study. Cardiology. 2003; 1:30-5.

48. Bakhtiary F, Schiemann M, Dzemali O, et al. Impact of patient-prosthesis mismatch and aortic valve design on coronary flow reserve after aortic valve replacement. J Am Coll Cardiol. 2007;49:790-6.
49. Timek TA, Green GR, Tibayan FA, et al. Aorto-mitral annular dynamics. Ann Thorac Surg. 2003;76:1944-50.

50. Nygaard H, Paulsen PK, Hasenkam JM, Kromann-Hansen O, Pedersen EM, Rovsing PE. Quantitation of the turbulent stress distribution downstream of normal, diseased and artificial aortic valves in humans. J Cardiothorac Surg. 1992;6: 609-17.

51. Kazui T, Izumoto H, Yoshioka K, Kawazoe K. Dynamic morphologic changes in the normal aortic annulus during systole and diastole. J Heart Valve Dis. 2006;15: 617-21.

52. Desai ND, Merin O, Cohen GN, et al. Long-term results of aortic valve replacement with the St. Jude Toronto stentless porcine valve. Ann Thorac Surg. 2004; 78:2076-83.

53. Bach DS, Goldman B, Verrier E, et al. Durability and prevalence of aortic regurgitation nine years after aortic valve replacement with the Toronto SPV stentless bioprosthesis. J Heart Valve Dis. 2004;13:64-72.

54. Bach DS, Cartier PC, Kon ND, Johnson KG, Deeb GM, Doty DB. Impact of im plant technique following freestyle stentless aortic valve replacement. Freestyle Valve Study Group. Ann Thorac Surg. 2002;74:1107-13.

55. Ennker JA, Albert AA, Rosendahl UP, Ennker IC, Dalladaku F, Florath I. Tenyear experience with stentless aortic valves: full-root versus subcoronary implantation. Ann Thorac Surg. 2008;85:445-53.

56. Borger MA, Prasongsukarn K, Armstrong S, Feindel CM, David TE. Stentless aortic valve reoperations: a surgical challenge. Ann Thorac Surg. 2007;84: 737-43.

\section{Discussion}

Dr Hartzell V. Schaff (Rochester, Minn). Thank you, Dr Miller, Dr Kron. I want to congratulate Dr Cohen on a beautiful presentation. $\mathrm{He}$ and his colleagues have provided important information on the 10-year follow-up of a comparative study of the stented and stentless valves. He has shown no difference in the mass regression when comparing the 2 groups. There is no real difference in hemodynamics, perhaps a 3-mm gradient, which was statistically significant but appears not to be clinically important. The most important feature is that there does not appear to be a difference in clinical outcome.

The limitations of the study are clear. It is a small group of patients, but I think that the strengths should be emphasized. If there is anyone from the US Food and Drug Administration here or if any of our colleagues consult for the Food and Drug Administration, this is really a model for how valve studies should be performed It is randomized, and importantly, the patients are stratified according to annular diameter and not to labeled valve size.

I have a few questions. Dr Miller asked that we take these in order. You found no difference in mass regression between the stented and stentless valves, but did you do any analysis that looks at the predictors of mass regression in the overall group? For example, is there any subgroup that might benefit from this small 3-mm gradient difference, such as those with more severe degrees of hypertrophy or hypertension?

Dr Cohen. We actually did, and although there was a slight beneficial trend in female subjects, in general, the numbers were too small to enable any conclusive statements.

Dr Schaff. And you found that the regurgitant orifice areas in the stentless group improved over time, but that was at the expense of an increased degree of aortic regurgitation in that group. Did you analyze valve areas in patients who had no aortic regurgitation at the end of follow-up?

Dr Cohen. I would say specifically no. However, we did exclude patients who had either moderate to moderate-severe aortic regurgitation. Therefore all of the patients we included in the echocardiographic follow-up had little or no residual AI. Those who did 
have more AI were excluded because we did not want to contaminate the findings with patients who had some evidence of valve dysfunction or valve deterioration.

Dr Schaff. It is also an interesting study in one final regard, and that is that it seems the most important findings are not the differences that are statistically significant but perhaps a nonsignificant difference that is clinically important; that is, the appearance that there is decreased durability of the stentless valves. The stentless valves were introduced with the idea that the flexibility might improve long-term durability. Can you comment on why you found the opposite?

Thank you.

Dr Cohen. Thank you, Dr Schaff. One of the things we did look at through MRI assessment was the flexibility of the aortic annulus after stented versus stentless valve implantation. The feeling was that when we initially implanted these valves there would be more flexibility in patients receiving stentless valves and that this would translate to improved durability. In fact, we were not able to find any differences or changes in the configuration of the annulus by MRI assessment.

As to why the patients receiving stentless valves had poor durability over time, there are 2 reasons. First, when the Toronto stentless porcine valve was initially introduced, there was no anticalcification treatment. Therefore, we found that our patients with stentless valves tended to have calcification of the leaflets somewhat earlier than those receiving pericardial valves. The other issue is that when we initially implanted the stentless valve, we really did not think much about the interrelation of a subcoronary implant with the aortic root. Obviously what we found, especially in patients with bicuspid aortic valves who were prone to aortic root dilatation over time, was that displacement of the commissures of the stentless valve caused eventual leaflet tears or what we define in our study as nonstructural valve dysfunctions. Those 2 issues were the ones that I think contributed to most of the failures in the patients receiving stentless valves.

Dr. D. Craig Miller (Stanford, Calif). Gideon, I might have missed it, but for which primary end points is this study adequately powered statistically to support this conclusion of no difference? Is there a chance of a type 2 or $\beta$ error here?

Dr Cohen. That is an excellent question. We were underpowered to make any definitive conclusions with respect to clinical outcomes. There is no question about that. Our primary and secondary outcomes were LV mass regression and functional outcome based on the DASI score, and we were adequately powered for those 2 outcomes.

Dr Joseph E. Bavaria (Philadelphia, Pa). I would amplify what Dr Schaff said about the beauty of this prospective randomized study. It was very nicely done and produced great 9-year data. We will learn a lot from it.

My question really is regarding the same thing Dr Schaff talked about, which is structural valve deterioration for this subcohort you have presented. There are fairly reasonable data coming out on the Freestyle root, as well as the full root Toronto valve, that if you perform full root operations, you do not get these structural valve deteriorations that you see in your study. Therefore I would like for you to comment on the controversy regarding full root versus subcoronary stentless implantation and as it pertains to early and midterm structural valve deterioration.

Dr Cohen. Thank you very much. That is an excellent question once again. There has been a lot of talk advocating full root replacements for isolated aortic valve disease, and there have been some series that have reported excellent outcomes with equal morbidity and mortality to that of just plain old aortic valve replacement.

To be honest with you, I am not sure we should be advocating full root replacement for isolated aortic valve disease. To me, that is tantamount to recommending total colectomy for acute appendicitis. It does not make much sense. Although there are certain groups that I am sure can achieve excellent outcomes, I am not sure that the average surgeon, myself included, is willing to submit his patients, most of whom are now 70 to 80 years of age or older, to full root replacement for isolated aortic valve disease, especially in the absence of definitive clinical evidence of benefit with stentless valves and a full root replacement.

Dr Thoralf Sundt (Rochester, Minn). Because you are looking at LV mass regression, and maybe you mentioned this and I missed it, a lot of your patients have hypertension, and we are well aware that hypertension can have as profound an effect on LV mass as the valve itself. How did you go about evaluating the adequacy of antihypertensive therapy in the 2 groups, are you sure that they were similar, so on and so forth?

Thank you very much.

Dr Cohen. We initially stratified our study by annular diameter, coronary disease, and surgeon. We did not stratify by hypertension because it is very difficult to diagnose or to definitively say that a patient has hypertension preoperatively because high blood pressure might be a physiologic response to aortic stenosis. Therefore we did not stratify ahead of time, and we hoped-and in fact it was the case because of the randomized nature of this study - that there were an equal number of hypertensive patients in both groups; actually, they were identical percentages.

I think that there is no question that hypertension-ongoing hypertension-might have had an effect; however, for all of our patients who were followed, we confirmed adequate control of hypertension postoperatively through frequent visits and close follow-up with cardiologists.

Dr Miller. I have one little bit of unsolicited advice worth exactly zero pesos. That MRI on the right, I will bet you a 6-pack that was a bicuspid valve and you should have replaced the tubular segment of the ascending aorta.

Dr Cohen. You are probably right. Thanks.

Dr Miller. Left a little guppy aneurysm behind in the context of bicuspid aortic valve disease. 


\section{Appendix 1. Echocardiographic parameters and calculations}

\section{EOA}

By reconfiguration of the continuity equation, aortic EOA is calculated as follows:

$$
\mathrm{EOA}=\left(\mathrm{CAS}_{\mathrm{LVOT}} \times \mathrm{TVI}_{\mathrm{LVOT}}\right) / \mathrm{TVI}_{\mathrm{AO}}\left(\mathrm{cm}^{2}\right),
$$

where $C S A_{L V O T}$ is defined as left ventricular outflow tract (LVOT) cross-sectional area $\left(\pi \mathrm{R}^{2} / 4\right)$ in square centimeters obtained from 2D measurement of LVOT diameter; $T V I_{L V O T}$ is defined as the time velocity integral of forward blood flow in centimeters derived from pulsed-wave (PW) Doppler scanning in the LVOT; and $T V I_{A O}$ is defined as the time velocity integral of forward blood flow in centimeters derived from transvalvular continuous-wave (CW) Doppler scanning.

\section{Cardiac output}

Cardiac output $(\mathrm{CO})$ is calculated by using the following formula:

$$
\mathrm{CO}=\left(\mathrm{TVI}_{\mathrm{LVOT}} \times \mathrm{CSA}_{\mathrm{LOVT}}\right) \times \mathrm{HR}(\text { in } \mathrm{L} / \mathrm{min}),
$$

where $T V I_{L V O T}$ is defined as the time velocity integral of forward blood flow in centimeters derived from PW Doppler scanning in the LVOT; $C S A_{L V O T}$ is defined as the LVOT cross-sectional area $\left(\pi \mathrm{R}^{2} / 4\right)$ in square centimeters obtained from 2D measurement of LVOT diameter; and $H R$ is defined as heart rate in beats per minute.

\section{Peak pressure gradient}

Peak velocities obtained from PW and CW Doppler scanning are converted into pressure gradients by using Bernoulli's equation as follows:

$$
\begin{array}{r}
\Delta \mathrm{P}_{\mathrm{PEAK}}=4\left(\mathrm{~V}_{2}^{2}-\mathrm{V}_{1}^{2}\right) \text { for an aortic valve peak systolic } \\
\text { pressure gradient in millimeters of mercury },
\end{array}
$$

where $V_{2}$ is defined as peak transvalvular velocity in meters per second as measured with CW Doppler scanning and $V_{1}$ is defined as peak velocity in the LVOT in meters per second, as measured with PW Doppler scanning.

\section{Mean pressure gradient}

Mean transvalvular pressure gradient is calculated by subtraction of the mean pressure proximal to the aortic valve from the mean distal pressure. Mean pressures are obtained by means of planimetry of the Doppler spectral envelope.

$\Delta \mathrm{P}_{\mathrm{MEAN}}=\left(P_{2}-P_{1}\right)$, mean transvalvular pressure gradient in millimeters of mercury,

where $P_{2}$ is defined as mean distal pressure in millimeters of mercury, as measured with CW Doppler scanning, and $P_{1}$ is defined as mean pressure in the LVOT in millimeters of mercury, as measured with PW Doppler scanning.

\section{LV mass}

$$
\begin{aligned}
\mathrm{LV} \text { mass } *= & 0.8 \times\left[1.04 \times(\mathrm{LVIDd}+\mathrm{PWTd})^{3}-(\mathrm{LVIDd})^{3}\right] \\
& +0.6 \mathrm{~g}
\end{aligned}
$$

where LVIDd is defined as LV internal dimension at enddiastole in centimeters; IVSd is defined as interventricular septal thickness at end-diastole in centimeters; and PWTd is defined as posterior wall thickness at end-diastole in centimeters.

*This formula for LV mass is based on the volume-corrected ASE cube method. ${ }^{10}$

\section{LV function}

The percentage of fractional shortening, when derived from M-mode measurements, is based on minor axis shortening and assumes the ventricle contracts symmetrically.

$$
\% \Delta \mathrm{D}=\left(\mathrm{LVIDd}-\mathrm{LVID}_{\mathrm{S}}\right) / \mathrm{LVIDd} \times 100 \%,
$$

where LVIDd is defined as LV internal dimension at enddiastole in centimeters and LVIDs is defined as LV internal dimension at end-systole in centimeters.

Velocity of circumferential fiber shortening, when derived from M-mode measurements, represents the velocity of fiber shortening in the minor axis rather than in the whole circumference.

Vcf $=($ LVIDd-LVIDs $) /$ LVIDd $\times$ LVET $)$ in circumferences per second

where LVIDd is defined as LV internal dimension at enddiastole in centimeters; LVIDs is defined as LV internal dimension at end-systole in centimeters; and LVET is defined as LV ejection time in milliseconds measured from the onset to the end of systolic flow. 